\title{
EL ADORATORIO DEL CERRO EL POTRO: ARQUEOLOGÍA DE ALTA MONTAÑA EN LA CORDILlERA DE COPIAPÓ, NORTE DE CHILE
}

\author{
Ricardo Moyano ${ }^{1}$
}

\section{$*$ Introducción}

Resumen

Se exponen los resultados del reconocimiento arqueológico de las nacientes del río Los Helados y del cerro El Potro, en el valle de Copiapó. El objetivo principal fue constatar evidencias descritas para la zona que dieran cuenta de una huaca prehispánica, como también definir la orientación orográfica de la arquitectura del centro metalúrgico Viña del Cerro. Los resultados sugieren que existieron prácticas culturales

vinculadas con la tradición andina de adorar a las montañas, que incluyeron ceremonias públicas en Viña del Cerro, así como ceremonias restringidas en el cerro El Potro y sus inmediaciones. Esta dualidad habría permitido manejar las relaciones de poder y reciprocidad entre los incas y los grupos locales, así como formar parte de ritos anuales de fertilidad, base de la cadena productiva minero-metalúrgica del valle del

río Copiapó

Palabras claves: cerro El Potro - Viña del Cerro - Tawantinsuyo - Copiapó.

Abstract

The archaeological survey carried out in the upper Los Helados river and in mount El Potro, confirms mountaineering and scholarly descriptions of evidence attesting to the existence of a pre-Columbian huaca, and contributes to explain the orographic architectural orientation of the Viña del Cerro metallurgical center. Our findings suggest Andean mountain cults were indeed carried out there, including public ceremonies in the center and more exclusive ones on the El Potro and its surroundings. Distinctly separate traces of Copiapó valley fertility rituals express the dual power and reciprocity relations established amongst the Incas and local groups, which sustained their mining-metallurgical activities in the area.

Key words: Potro mountain - Viña del Cerro - Tawantinsuyo - Copiapó.

Recibido: mayo 2008. Aceptado: marzo 2009
En los Andes Meridionales se considera a las montañas como lugares sagrados por estar vinculadas con los antepasados y espíritus tutelares, los fenómenos metereológicos y las actividades agrícolas y ganaderas, las riquezas del inframundo, así como con la suerte y salud de las personas (Martínez 1976, 1983; Reinhard 1983).

El Tawantinsuyo habría incorporado la costumbre de adorar a las montañas a su religión estatal como parte de su estrategia de dominación. Este proceso involucró la subordinación de la mano de obra local para construir o mejorar los tambos, plataformas y caminos; la utilización de objetos y productos de alto valor suntuario en las ofrendas, e incluso, sacrificios humanos; y la participación restringida de las élites y grupos locales en las ceremonias destinadas a adorar a los cerros (Ceruti 1999).

La cuenca del río Copiapó se ubica en la región de Atacama, norte de Chile, entre los $26^{\circ} 45^{\prime}$ y $28^{\circ} 30^{\prime}$ Lat. S, $69^{\circ} 03^{\prime}$ y $70^{\circ} 57^{\prime}$ Long. O. Limita al norte con la hoya hidrográfica del río Salado y pequeñas cuencas costeras de interfluvio, al oriente con las provincias argentinas de Catamarca y La Rioja, y por el sur con la parte alta del río Huasco. Por ubicarse al sur del desierto de Atacama, posee un clima desértico transicional con escasas precipitaciones y de preferencia en la alta cordillera, temperaturas moderadas, escasa humedad ambiental y una alta radiación solar (Niemeyer 1981).

${ }^{1}$ Escuela Nacional de Antropología e Historia. Periférico Sur y Zapote s/nº. Col. Isidro Favela, México D.F., CP 14030, MÉXICO. Email: mundosubterraneo@hotmail.com 


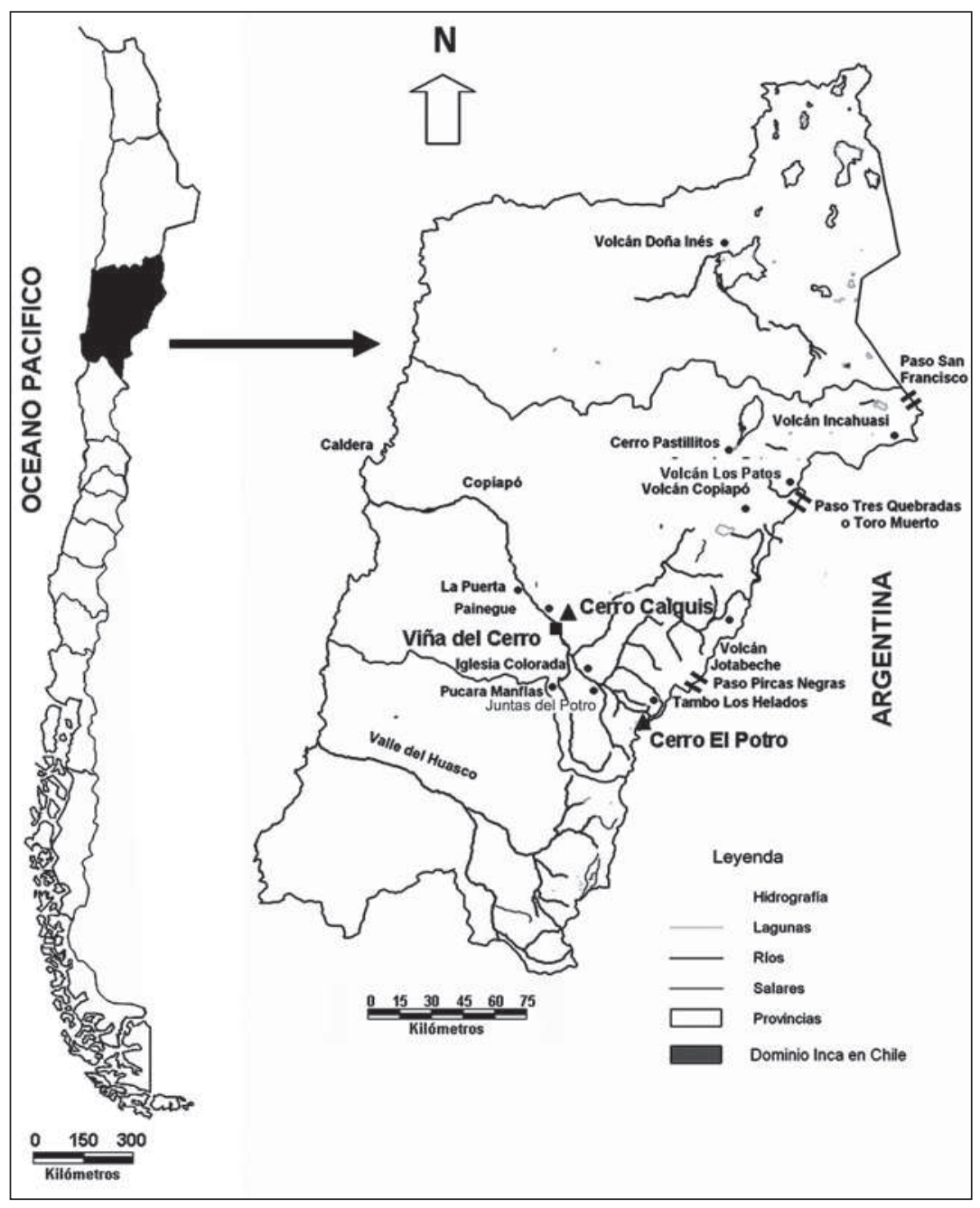

Figura 1. Mapa de ubicación general.

En una fecha cercana a 1470 DC el valle de Copiapó pasó a formar parte del Tawantinsuyo, lo cual significó el traslado de mitimaes diaguitas desde los valles del Elqui y Huasco hacia importantes centros administrativos y productivos ubicados en el sector medio y alto de la cuenca del Copiapó (Castillo 1997), así como la incorporación de las huaca locales al culto solar y al incanato (Reinhard 1991).

En la región de Atacama existen a lo menos 20 sitios arqueológicos con características de adoratorio distribuidos entre la línea de costa y la alta cordillera de los Andes (Cervellino com. pers. 2005). Estos sitios en su mayor parte han sido descritos desde finales de la década de 1930, gracias a las primeras ascensiones deporti- vas y prospecciones arqueológicas en la zona (Beorchia 1985).

Estudios sistemáticos fueron realizados en el volcán Copiapó y Jotabeche a finales de la década de 1980 (Reinhard 1991, 1992, 2001). Recientemente, trabajos de campo han constatado la existencia de sitios arqueológicos en las cumbres de los cerros Pastillitos y Los Patos (Moyano 2009), así como interesantes pistas sobre la adoración a las montañas a partir del período Formativo en la vertiente argentina del Incahuasi (Hershey com. pers. 2008).

En esta oportunidad, se intenta dar cuenta del avance de las investigaciones arqueológicas llevadas a cabo en la alta cordillera de Copiapó, en particular en la cuenca 


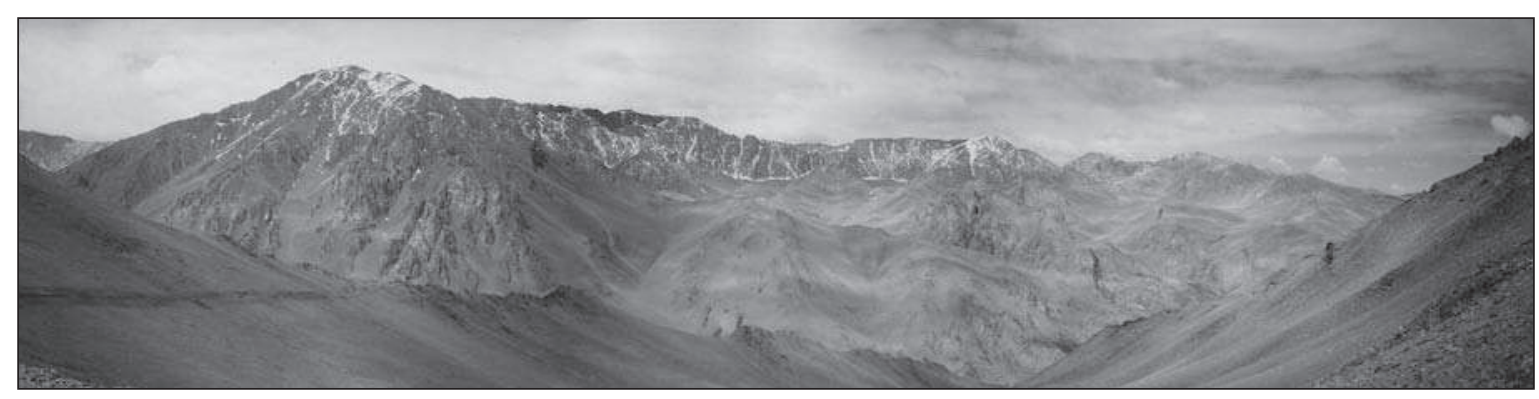

Figura 2. Vista del cerro El Potro desde el portezuelo Los Helados.

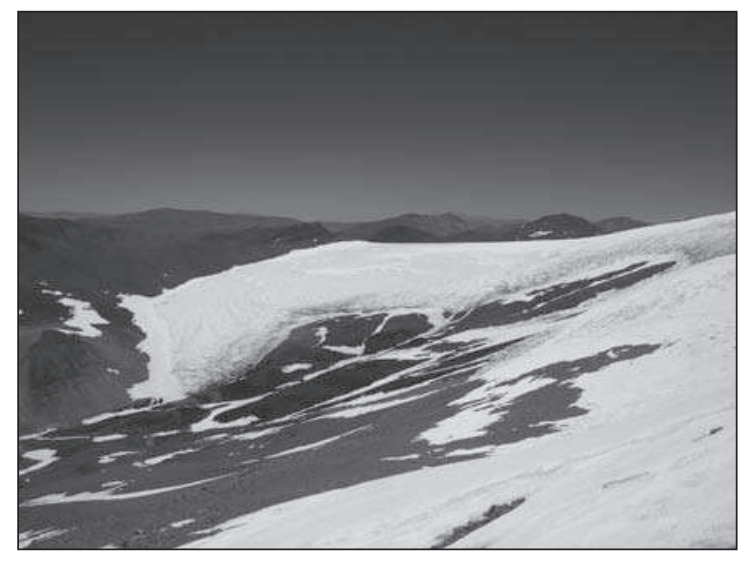

Figura 3. Vista general del glaciar Los Helados.

del río Los Helados y cerro El Potro. Nuestro objetivo es verificar los antecedentes que mencionaban de una posible huaca incaica ubicada en la cumbre del cerro El Potro (Beorchia 1985), constatar recientes hallazgos realizados desde la vertiente chilena, así como dar respuesta a las orientaciones orográficas de la arquitectura ceremonial y doméstica del centro metalúrgico Viña del Cerro (Moyano 2006, 2009 Ms). ${ }^{2}$

\section{* Cerro el potro (5886 m.snm)}

El Potro es una montaña ubicada a $165 \mathrm{~km}$ al sureste de la ciudad de Copiapó, en la región de Atacama, en el límite entre Chile y Argentina (UTM 438277 E / $6858998 \mathrm{~N}$ ). Desde su cumbre principal se descuelga el glaciar Los Helados, que da origen a los ríos del Medio y Pulido, afluentes del río Copiapó, primera cuenca

\footnotetext{
2 Esta investigación fue parte de la memoria de título del autor (Moyano 2006).
}

exorreica al sur del despoblado de Atacama (Figura 1). Las primeras referencias de la zona de estudio las entrega el geólogo francés Pissis, quien en su viaje de 1849 describe al Potro como "una elevada serranía que se extiende en la dirección de este a oeste [...] cuya altitud llega a $5584 \mathrm{~m}$ ", donde "[...] las nieves permanentes se mantienen a $5200 \mathrm{~m}$ " (1875: 11, 198). Tiempo después, Risopatrón agrega que el lugar es "[...] traquítico, ofrece nieve perpetua a contar desde los $5200 \mathrm{~m}$ i se levanta a 5830 m de altitud, en el cordón limitáneo con la Argentina, en los orígenes del río de aquel nombre, del de Pulido" (1924: 696) (Figuras 2 y3). En Argentina, Schobinger y miembros de la Universidad Nacional de Cuyo visitaron en 1966 un conjunto de 14 pircas ubicadas en el arroyo La Paila (Beorchia 1985). En 1971 una expedición del club andino Mercedario de San Juan, además de las estructuras descritas por Schobinger, registra un conjunto de pircas circulares y elípticas, puntas de proyectil, cerámica Diaguita-Inca y un rectángulo ceremonial en la unión del arroyo de Peña Negra y el río Blanco, cercanos a un tramo del Qhapaqñan. En diciembre del mismo año, Beorchia y otros andinistas encuentran a $10 \mathrm{~m}$ de la cumbre una varilla de madera de $90 \mathrm{~cm}$ de largo y extremo inferior redondeado por desgaste, lo que podría suponer la existencia de un "probable santuario incaico de alta montaña” (Beorchia 1985: 183-185). A estos hallazgos se agrega recientemente una vasija globular con asa lateral, base columnar y pie circular encontrada en el filo sureste de la montaña, a 4500 m.snm (Beorchia 2001).

En Chile desde la década de 1970 existen registros de estructuras y tamberías "diaguita incaicas" en El Torín, río Los Helados y el paso de la Ollita (Niemeyer 1981, 1986). También se han descrito estructuras pircadas, un rectángulo ceremonial de 10 x $5 \mathrm{~m}$ con grandes vigas de madera de 2 a $3 \mathrm{~m}$ de largo ubicadas junto a la pared que

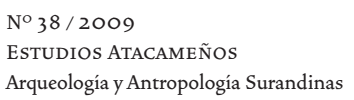


enfrenta al valle de Copiapó, a 4600 m.snm; además, madera, cuerdas vegetales y una plataforma en el filo noroeste, a $5500 \mathrm{~m} . \mathrm{snm}$, y un sendero -al parecer, prehispánico - junto al glaciar a 5200 m.snm, que comunicaría la cuenca de Los Helados con el río Los Mogotes en Argentina (Moyano 2006).

\section{* La adoración a las montañas}

En los Andes, elementos de la naturaleza como lagos, vertientes, rocas, ríos y montañas han sido considerados desde tiempos prehispánicos como sagrados o huacas (Zuidema 1995 [1964]). En los Andes Meridionales, a los cerros se les reconoce como espíritus tutelares, de naturaleza bisexual y alto poder genésico o fecundador. Por esta razón, se les vincula con el culto solar, los fenómenos meteorológicos, la producción agrícola y ganadera, las riquezas del inframundo, así como con la existencia de caminos y marcadores del paisaje (Martínez 1976; Castro et al. 1986; Castro y Aldunate 2003). Reciben diferentes nombres dependiendo del área geográfica en la que nos encontremos: awkillu en Huanuco, wamani en Ayacucho y apu en Cusco, Perú; así como machula, achachila o mallku en distintas regiones de Bolivia y del norte de Chile (Martínez 1983).

Este fenómeno cultural podría al menos remontarse al período Intermedio Temprano o Formativo (ca. 0-500/600 DC) y al período Medio (600-1000 DC) en el altiplano peruano-boliviano (Leoni 2005; Williams y Nash 2006). Sin embargo, hasta hoy se postula que los principales adoratorios ${ }^{3}$, al menos en la parte meridional de los Andes, fueron erigidos durante la expansión del Tawantinsuyo, después de 1470 DC (Le Paige 1978; Barón y Reinhard 1981; Reinhard 1983, 1991, 1992; Beorchia 1985; Ceruti 1997, 1999, 2003; Schobinger 1999, 2001).

A partir de esta fecha dicha práctica adquirió características nunca antes vistas, e incluyó la construcción y/o mejora de redes viales, estructuras, tambos y plataformas, además de ofrendas de alto valor, como animales (llamas, alpacas y cuyes), madera, plumas, textiles, cerámica,

3 Utilizamos "adoratorio" en vez de "santuario" para evitar la carga simbólica de este término cristiano-occidental (Cervellino 2001: 183). hojas de coca, chicha, figurillas de Spondylus, plata y oro (de formas antropo y zoomorfas), y en los casos más excepcionales, sacrificios humanos o capacochas (Reinhard 1983; Beorchia 1985; Ceruti 1997, 1999).

La arqueología de alta montaña ha nacido como una subdisciplina científico-deportiva motivada por el estudio de los adoratorios de altura. Estos se definen como el conjunto diferencial de artefactos, ecofactos y rasgos, que pueden variar de un simple fogón a un complejo arquitectónico o sacrificio humano, ubicado a una altitud variable, y que se encuentran asociados a prácticas rituales en los Andes (Castro et al. 1986).

La etnoarqueología entrega herramientas teórico-metodológicas que permiten diferenciar el registro arqueológico de alta montaña en las siguientes categorías (Ceruti 1999: 55-73):

a) Centros de peregrinaje: Montañas que presentan una distribución estratégica de instalaciones logísticas (campamentos y caminos), así como arquitectura ceremonial de considerable perdurabilidad y visibilidad, ubicada sobre superficies amplias y extensas que permiten la participación masiva y periódica de peregrinos.

b) Ofrendatorios: Lugares emplazados sobre superficies abruptas y reducidas, sin arquitectura ceremonial ni instalaciones logísticas de gran envergadura. Las ascensiones hasta ellos habrían sido esporádicas y de carácter restringido, y con un gasto menor de energía en comparación con los centros de peregrinaje.

Estas categorías suponen la idea que cada sociedad puede ser entendida como un conjunto de agentes en conflicto, donde cada grupo aspira a aumentar o mantener un determinando "poder" o capacidad de movilizar recursos. Los intentos por preservar e incrementar dicho poder se entenderían como estrategias de dominación, mientras que los intentos por modificar las condiciones existentes se traducirán en estrategias de resistencia. En este sentido, las prácticas rituales vinculadas con la adoración a las montañas se explicarían como la instrumentalización de las distintas estrategias de dominación y resistencia, entre los incas y los grupos locales (Ceruti 1999: 45-53). 
Trabajos recientes han identificado a estos cerros como sagrados por su semejanza formal aparente con rostros y cuerpos humanos o de animales. Para explicar lo anterior se menciona tres fenómenos psicológicos: Pareidolia, que permite de manera automática reconocer una semejanza formal; Apofenia, que permite establecer relaciones complejas entre fenómenos no directamente relacionados; y Hierofanía, que lleva a identificar esta forma natural reconocida y las subsecuentes relaciones con un hecho numinoso o una manifestación divina (Bustamante 2006, 2007a, 2007b).

En este sentido, resulta sugerente que el cerro El Potro tenga el nombre de un animal y que la forma general del cerro observado desde Viña del Cerro parezca el lomo de un animal. No existen registros del nombre originario, pero el topónimo actual sugiere que quienes lo observan reconocen la forma que origina el nombre. ${ }^{4}$

Actualmente se conocen más de 170 sitios arqueológicos con características de adoratorio distribuidos entre el sur de Perú y el centro norte de Chile y Argentina. Entre ellos destacan por su espectacularidad, Coropuna (6377 m.snm), Chachani (6057 m.snm) y Picchu Picchu (5634 m.snm) en Perú; Licancabur (5921 m.snm) en la frontera de chilena-boliviana; Llullaillaco (6739 m.snm), El Toro (6160 m.snm) y Mercedario (6770 m.snm) entre Chile y Argentina; Aconcagua (6959 m.snm) y El Plomo (5430 m.snm), en el extremo sur del antiguo Tawantinsuyo (Beorchia 2001).

En la región de Atacama, además del Potro, destacan los volcanes Copiapó (6072 m.snm)5 y nevado Jotabeche

4 En códices mesoamericanos como el Vindobonensis (hojas 9 y 10), los cerros son dibujados registrando su forma aparente, así en su cumbre presentan la forma de un animal, un dios o un símbolo. Cerros como el Matlalcueye, Ajusco, Popocatepetl e Iztaccihuatl tienen en sus cumbres sitios arqueológicos, y los registros históricos señalan que fueron sacralizados debido a su forma aparente con rostros o cuerpos de personas de género masculino o femenino (Bustamante 2008). En el caso de los incas no hay registros equivalentes a los códices aztecas, sin embargo, el significado de la sacralización de los cerros señalaría que se trata de fenómenos análogos.

5 Entre 1985 y 1988 se excavaron las dos plataformas descritas en el volcán Copiapó por la expedición polaca a finales de la década de 1930. Entre los materiales recuperados hay huesos calcinados de camélidos, carbón, pasto, plumas, pelo humano, trozos de
(5862 m.snm), estudiados a fines de la década de 1980 (Reinhard 1991, 1992, 2001), Incahuasi "casa del Inka" (6621 m.snm) y Doña Inés (5070 m.snm) (Beorchia 2001), y los adoratorios de Pastillitos (5093 m.snm) y Los Patos (6249 m.snm) (Moyano 2009).

\section{* El tawantinsuyo en copiapó}

El Tawantinsuyo en Copiapó abarcaba desde la costa hasta las altas cumbres de la cordillera de los Andes.7 En esta cuenca se tiene registro de al menos 50 establecimientos correspondientes a las categorías de cementerio, pucara, centro administrativo, tambo o poblado, puesto de control, paradero de caza, red vial, arte rupestre, adoratorio, yacimiento minero, centro metalúrgico y observatorio astronómico (Moyano 2006).

El río Copiapó, desde el Formativo ha constituido un espacio de interacción multiétnica donde convergían grupos del Noroeste Argentino, centro norte chileno y sur de Bolivia, lo que habría motivado el surgimiento y desarrollo de una de las expresiones culturales más fuertes previas al Tawantinsuyo, la cultura Copiapó. Ésta se define como una sociedad agropastoril que aprovechó los sectores medios y altos de la cuenca del río Copiapó desde 1200 DC. Desde el punto de vista arqueológico, se carac-

Spondylus, sogas vegetales, hojas de coca, charqui, vellón de vicuña, un ala de libélula, frutos de chañar, dos roedores, piedras elongadas, además de figurillas antropo y zoomorfas en plata y Spondylus en las ofrendas (Reinhard 1991, 1992).

6 Durante una excavación realizada en 1991, en la cumbre se encontró una estatuilla incaica de oro laminado con atavíos enterrada bajo un grupo de piedras (Delgado 2001: 276). Trabajos recientes dan cuenta también de otro par de sitios en la cumbre, todavía sin excavar, estructuras pircadas en el portezuelo Incahuasi-Fraile (¿incaicas?), además de sitios de los períodos Arcaico y Formativo en las inmediaciones del volcán, inclusive a más de $5000 \mathrm{~m} . \mathrm{snm}$ (Hershey com. pers. 2008).

7 La evidencia etnohistórica señala a la llegada de Pedro de Valdivia ( siglo XVI), el valle de Copiapó estaba bajo el control de los señores Aldequín y Gualenica, sucesores de Montriri, quienes estaban organizados en sistema político dual. El cacique Aldequín sería el señor de Copayapu (Copiapó) hacia el mar, incluyendo seguramente la costa cercana a Caldera y la desembocadura del río Copiapó. Mientras que el cacique Gualenica ocuparía la parte superior del valle Camasquil. Este incluiría los poblados y cementerios de Hornitos, La Puerta, Punta Brava, Painegue, Viña del Cerro y Choliguin-Iglesia Colorada (Urízar $2002 \mathrm{Ms}$ ). 
teriza por poblados aglutinados, pucara, corrales, campos de cultivo, manejo eficiente de la lítica, metalurgia y trabajo en madera, además de la alfarería Negro sobre Rojo o Ante y Punta Brava (Castillo 1997).

El Tawantinsuyo habría controlado la cuenca del río Copiapó a través de mitimaes trasladados desde Huasco y Elqui, e instalados sobre antiguos reductos Copiapó, como Punta Brava, La Puerta, Iglesia Colorada y Manflas. Estos habrían construido Viña del Cerro, un centro productivo de importancia estatal (Niemeyer et al. 1993; Niemeyer 1986; Castillo 1997).

En el caso de los pucara de Punta Brava y Manflas, el control militar se habría ejercido desde lugares especialmente construidos sobre las cimas de algunas colinas, donde era posible tener buena visibilidad y controlar las rutas de tráfico en el valle de Copiapó.

Particularmente en Manflas, destaca un adoratorio incaico en la cumbre del pucara, una "guaca-fortaleza" según la definición de Stehberg y Sotomayor (1999). Durante las excavaciones realizadas por Niemeyer y colaboradores (2003 Ms) en una plataforma de origen preincaica, se recuperaron además de cerámica local tipo Punta Brava y Copiapó, dos figurillas en Spondylus (miniaturas de llama y de mujer), dos tupu de plata, y una lámina de oro y plata.

$\mathrm{Al}$ respecto Castillo (com. pers. 2006), haciendo alusión también a los hallazgos de otra huaca incaica en la isla Guacolda en la desembocadura del río Huasco, sugiere que los incas no solo eligieron cerros altos como el Copiapó y el Jotabeche para instalar sus adoratorios, sino también aquellos elementos que resaltaban en el paisaje local para instalar sus huacas.

En el área cercana al cerro El Potro se edificó el tambo de Los Helados a $3730 \mathrm{~m} . \mathrm{snm}$, con una arquitectura típica del momento de aculturación diaguita-inca, es decir, con cimientos pircados de planta rectangular y muros de dos hiladas de piedra semicanteadas ligadas con argamasa de barro (Niemeyer 1986).

Un poco más al norte, en la ruta que va desde Iglesia Colorada al paso de la Ollita, se encuentra el tambo Caserones. En el lugar además de arquitectura y cerámica tardía se constató un yacimiento minero que seguramente fue explotado por los incas. Niemeyer y colaboradores (1993) sugieren además, que este mineral pudo ser transportado hasta la fundición de Viña del Cerro, donde se proceso y luego distribuyó a otras partes del imperio.

Desde el paso de la Ollita a 4700 m.snm, es posible acceder a la provincia argentina de La Rioja. En este paso se identificó cerámica prehispánica Ánimas, Copiapó y Diaguita-Inca, además de un tramo de camino emplantillado de 2.5 a $3 \mathrm{~m}$ de ancho en las cercanías de las tamberías de La Ollita A (Niemeyer et al. 1993).

Otros pasos en la alta cordillera son los de Peña Negra, Pircas Negras, Comecaballos y Peñasco de Diego. Estos tienen en común que se debe traspasar la cordillera del Pulido para llegar a la tambería Vega del Obispo, donde es posible elegir entre la ruta del río Cachitos y llegar al paso fronterizo de Peña Negra a 4300 m.snm, o bien, trasponer el paso de Las Carretas para acceder a los pasos de Pircas Negras, Comecaballos y Peñasco de Diego. Aparentemente, el paso de Pircas Negras fue el más frecuentado, ya que allí existen estructuras pircadas asociadas a cerámica Copiapó y Diaguita-Inca (Niemeyer 1986; Niemeyer et al. 1993).

Alguno de estos "ramales trasandinos", pudo conectar la zona de Copiapó con los centros administrativos de El Shinkal y Tambería del Inka en el lado argentino (Stehberg 1995); y simbólicamente pudo también representar la "hipóstasis del camino solar" por su orientación este-oeste (Schobinger 1986), o estar relacionados con la división de espacios y distintos grupos étnicos a través del sistema de ceques (Hyslop 1992).

\section{* La orientación orográfica en viña del cerro}

Viña del Cerro, "Cabeza de Puerco" o "Apacheta", fue un centro metalúrgico diaguita incaico (1470-1536 DC) ubicado en el sector medio de la cuenca del río Copiapó (UTM 398555 E/ 6913172 N, 1092 m.snm). Se emplaza sobre un espolón rocoso, $50 \mathrm{~m}$ sobre la caja del río Copiapó, a los pies del cerro Calquis. Trabajos etnohistóricos suponen además la existencia de un pueblo de indios conocido históricamente como Painegue, ubicado en las

$\mathrm{N}^{\circ} 38 / 2009$

EstUdios ATACAMEÑOS

Arqueología y Antropología Surandinas 
cercanías del actual poblado de San Antonio, $5 \mathrm{~km}$ al noroeste de Viña del Cerro (Urízar $2002 \mathrm{Ms}$ ).

El establecimiento Viña del Cerro se compone de cuatro unidades arquitectónicas: un grupo de 26 huayra u hornos de fundición (unidad C) ${ }^{8}$, un puesto de control (uni$\mathrm{dad} B$ ), una pequeña estructura para el aprovisionamiento de agua (unidad D), y una gran plaza o cancha (unidad A). Esta última se ubica en el sector más plano y amplio del espolón rocoso, y corresponde a un espacio de 58.5 $\mathrm{x} 52 \mathrm{~m}$ construidos en barro, piedra y adobe, compuesto por dos conjuntos arquitectónicos: el campamento (seis unidades residenciales y tres patios secundarios) y una plataforma interpretada como ushnu (Niemeyer 1986; Niemeyer et al. 1993).

La plataforma que podría haber formado parte del ushnu ${ }^{9}$, es de planta trapezoidal, muros de $6 \mathrm{~m}$ de largo como promedio, construida en barro y piedra, $y$ presenta una escalera de $1.4 \mathrm{~m}$ de ancho y siete peldaños en el muro suroeste. Para ella se ha sugerido que habría cumplido funciones políticas y administrati-

\footnotetext{
8 Las huayra se encuentran distribuidas en tres hileras paralelas en dirección SO-NE, y están construidas sobre un emplantillado de piedras y adobe que sobresale $30 \mathrm{~cm}$ del suelo, con un diámetro promedio de 2 a $3 \mathrm{~m}$. Sus formas van de circulares a elípticas, y al parecer, no habrían tenido una sección aérea permanente. Cuando en 1968 se excavó y realizó el levantamiento definitivo del sitio, la gran mayoría de las huayra ya estaban destruidas por la acción de huaqueros en busca de minerales y escoria (Niemeyer 1986).

9 Meddens (1997: 7) señala que los ushnu estarían "relacionados con el agua que baja del cielo a las montañas, es decir, con un culto a la fertilidad [donde] los ushnu actuarían como reguladores del clima". Pino (2005: 146), a partir de un trabajo etnoarqueológico en la Sierra Central de Perú vincula a estos lugares con "huecos, subsuelo, ruinas, pircas, lugares donde se encuentran los muertos, lugares donde se encuentran los gentiles, lugares peligrosos donde salen enfermedades, lugares donde filtra el agua, pozos, lugar con muchos cascajos, lugar de puras piedras o plataformas en cerros muy altos". Mientras que Zuidema (2009), combinando las descripciones de los cronistas Pizarro, Betanzos, Anónimo y Molina plantea que el ushnu podría haber tenido tres componentes: un pilón, una plataforma y posiblemente un pilar. Es enfático en afirmar que por importante que haya sido el ushnu de la plaza de Haucaypata (Cusco), correspondía a un tipo de huaca que podía darse en múltiples números en pueblos y aldeas; y que debiera distinguirse este uso de su variante imperial, ya que en la época incaica o colonial (y después) el término llegó a ser aplicado inclusive a la pirámide de Vilcas Huamán o a la plataforma de Huanuco Viejo, como sugiriera Hyslop (1990).
}

vas, relacionadas con la contabilidad y la producción metalúrgica (Niemeyer 1986; Niemeyer et al. 1993).10

Una revisión general de la cerámica recuperada de la plataforma indica que la totalidad está corresponde al tipo local Punta Brava. No se encontraron fragmentos de cerámica Copiapó Negro sobre Rojo o Ante, o DiaguitaInca, y a juzgar por los grandes contenedores de líquidos, podría suponer funciones domésticas. Otra posibilidad es que Viña del Cerro, al igual que otros sitios incaicos de la región, estuviera construido sobre un antiguo reducto Copiapó, lo que explicaría los de fragmentos de cerámica local que están insertos en sus muros de piedra y barro (Moyano 2006: 174). ${ }^{11}$

Recientemente hemos propuesto la posibilidad que Viña del Cerro en su conjunto fuera un observatorio solar de horizonte y escenario para adorar a las montañas locales (Moyano 2006, 2009 Ms). Lo anterior se sustenta en la existencia de marcadores naturales de horizonte para la salida del Sol en el solsticio de diciembre (SSSD) y para la puesta del Sol en el solsticio de junio (PSSJ) (Figura 4). En el lugar también se constató la orientación orográfica de la arquitectura ceremonial y doméstica de la unidad $\mathrm{A}$, donde los muros de la plataforma y los vanos de acceso a la cancha, los patios secundarios y unidades residenciales se orientan hacia los cerros Calquis y a un sector cercano a la salida del Sol en el solsticio de junio (SSSJ) (acimut $67^{\circ}$ ), así como hacia la pared del cerro El Potro (acimut $152^{\circ}$ ) (Figura 5).

\section{Consideraciones metodológicas}

La ascensión y reconocimiento arqueológico del cerro El Potro y la naciente del río Los Helados, se realizaron

\footnotetext{
${ }^{10}$ Algunos antecedentes permiten pensar que la plataforma podría haber sido el lugar de entierro de un ser humano en tiempos históricos, y además estar vinculada a través de un sistema de drenaje, posiblemente subterráneo, con un pequeño vano en el muro suroeste del gran patio o cancha (Moyano 2006, 2009 Ms).

${ }^{11}$ Entre la cerámica recuperada de la excavación de Viña del Cerro destaca el tipo local Punta Brava con $71.2 \%$, que corresponde a grandes vasijas contenedoras de granos y líquidos; la cerámica Copiapó, con sus variantes Negro sobre Rojo y Crema con 14.7\%; el tipo corriente Café Gris Alisado con 9.2\%; y la cerámica Diaguita con aculturación incaica, Negro sobre Crema o Negro y Rojo sobre Crema, además de Negro Bruñido, que en conjunto alcanzan $3 \%$. Estas últimas corresponden a kero, aríbalos, aribaloides y escudillas extendidas (Castillo 1997: 237).
} 


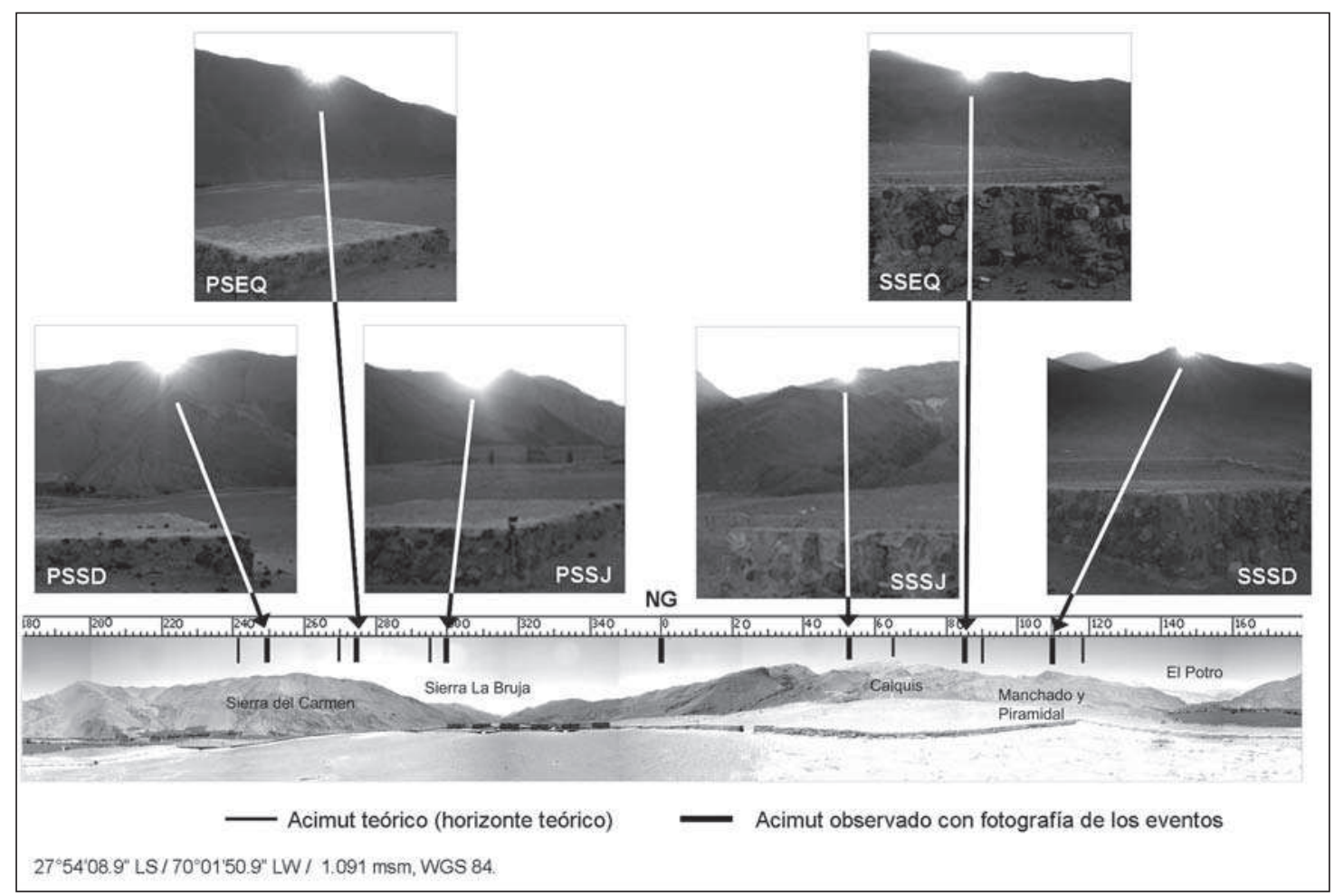

Figura 4. Fotografía panorámica $\left(360^{\circ}\right)$ de Viña del Cerro, y fotografías de la observación solar a simple vista.

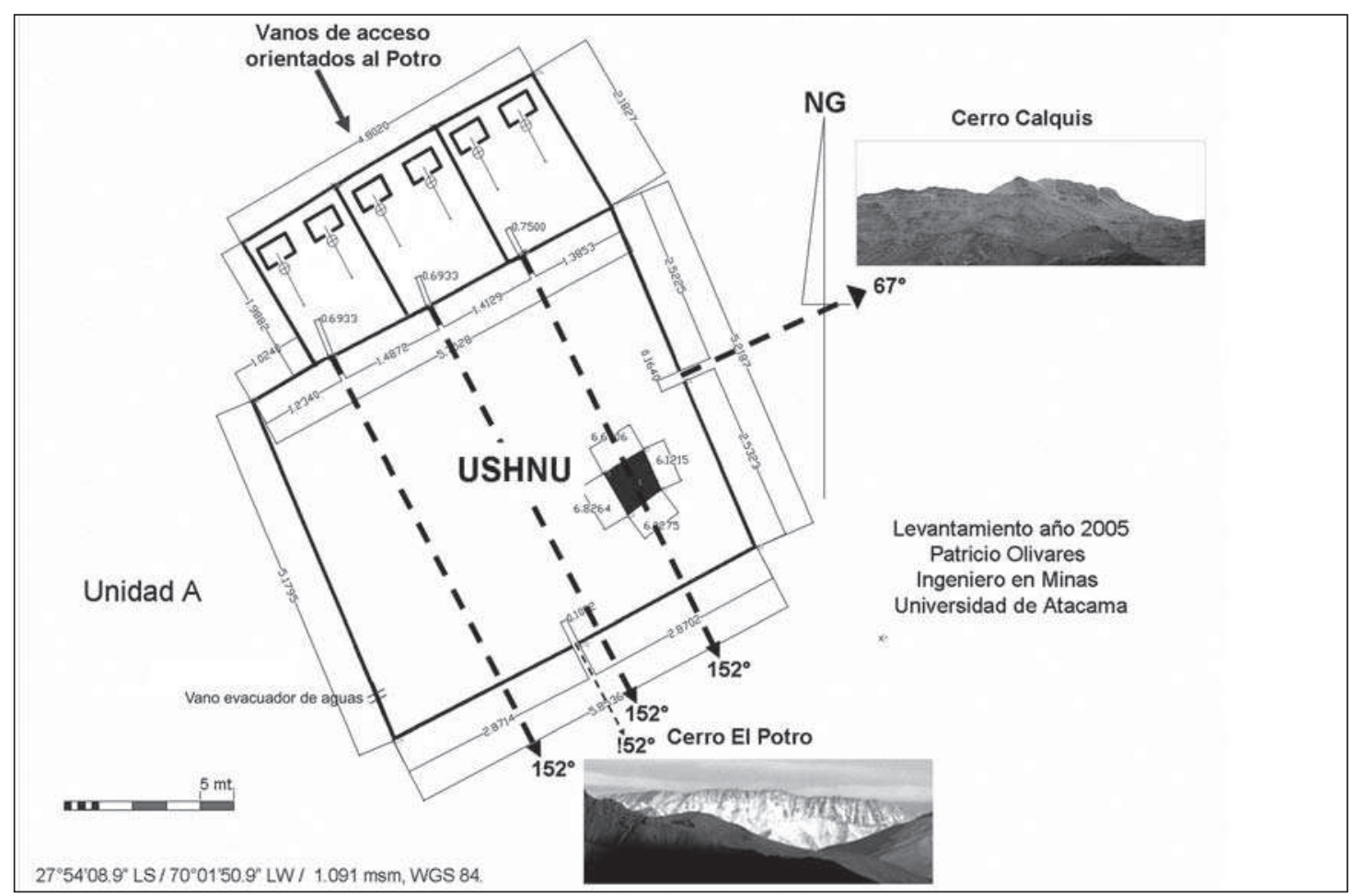

Figura 5. Unidad A del centro metalúrgico Viña del Cerro.

46 ESTUDios ATACAMEÑos

Arqueología y Antropología Surandinas 
entre los días 7 y 15 de diciembre de 2004, y 13 y 19 de diciembre de 2005. El itinerario partió desde la ciudad de Copiapó, luego nos trasladamos $120 \mathrm{~km}$ al sureste para llegar a Iglesia Colorada a $1500 \mathrm{~m} . \mathrm{snm}$, donde se continuó a Juntas del Potro (1816 m.snm) y a los caseríos de La Semilla (2200 m.snm) y La Cruzada (2579 m.snm), para cruzar el portezuelo Los Helados (4400 m.snm) distante $175 \mathrm{~km}$ de Copiapó, y bajar al río del mismo nombre, para finalmente comenzar el acercamiento desde la cota 4500 m.snm. ${ }^{12}$

Por las condiciones de desnivel y altitud (cota máxima 5886 m.snm) fue necesario en cada campaña tomar al menos dos días para aclimatar a los 4500 m.snm, en el campamento base. Esto nos dio tiempo de llevar parte de la carga hasta el campamento 1 , a una cota aproximada de $5000 \mathrm{~m} . \mathrm{snm}$, desde donde se abordó la cumbre principal, el filo de la pared, la cumbre norte y el portezuelo identificado junto al glaciar Los Helados.

Se dejó para los últimos días el reconocimiento de la cuenca del río Los Helados y la laguna homónima, de manera de realizar el mayor gasto físico los primeros días de cada expedición.

Se georreferenciaron (Datum WGS 84), fotografiaron y describieron los recursos arqueológicos e históricos de la zona. Los resultados del reconocimiento arqueológico se encuentran supeditados a las condiciones del terreno (visibilidad, acceso y distancia), al factor tiempo y a la dinámica de los agentes naturales del sector (precipitaciones, deshielos, rodados y avalanchas).

\section{$*$ Resultados}

Durante la expedición del año 2004 se ascendió la cumbre principal del cerro El Potro desde un campamento

\footnotetext{
12 Como parte del proyecto minero binacional argentino-chileno se ha dado curso a la fase "Proyecto Prospección Minera Vicuña, Sector Los Helados" (Minera Frontera del Oro SCM). Como resultado se ha habilitado provisionalmente el paso fronterizo Nacientes del Bermejo, ubicado $6.65 \mathrm{~km}$ lineales al noreste de la cumbre del cerro El Potro, superándose los $450 \mathrm{~m}$ de desnivel entre la base y la parte superior de la cascada a través de un camino en zigzag hasta la cota $5000 \mathrm{~m} . \mathrm{snm}$ en las inmediaciones del glaciar Los Helados (Cantarutti $2006 \mathrm{Ms}$ ).
}

instalado a 5200 m.snm. Para ello, primero fue necesario alcanzar el filo de la pared a los $5500 \mathrm{~m}$.snm y luego tomar rumbo al sur y cruzar el glaciar Los Helados desde la cota $5700 \mathrm{~m} . \mathrm{snm}$.

La cumbre (UTM 438277 E/ 6858998 N, 5886 m.snm) corresponde a una pequeña explanada libre de hielo, desde donde es posible apreciar sin dificultad las viñas de Iglesia Colorada, gran parte del valle de Copiapó y la cordillera de los Andes. En el lado chileno destacan de sur a norte el cerro El Toro, cordillera de Manflas, cerro Cantaritos, cerro Los Helados, nevado Tres Cruces y volcán Ojos del Salado. Mientras que en lado argentinodestacan las cumbres del Pissis, Bonete y Mogote. ${ }^{13}$

En diciembre de 2005 la prospección entregó los primeros resultados positivos, dando cuenta de una plataforma en el filo norte de la montaña a $5535 \mathrm{~m} . s n m$ (UTM 440489 E / 6863023 N) (Figura 6a). Se trata de un semicírculo de medidas internas $3.2 \times 3 \mathrm{~m}$ y $20 \mathrm{~cm}$ de alto. Sus paramentos sur y norte están formados por un muro doble con relleno, mientras el muro este se compone de un aterrazado artificial sobre la roca madre. La plataforma tiene una orientación este-oeste y fue rellenada con pequeñas rocas de andesita negras traídas desde las cercanías. En su interior presenta dos sectores con evidencias de saqueo, uno mayor al oeste y otro menor al este. La fosa mayor presenta en su interior un conjunto de piedras intencionalmente colocadas, tal vez con el fin de enterrar algún tipo de ofrendas (Figuras 6 b y $6 c$ ). ${ }^{14}$

En superficie no se observó material cultural y tampoco la pila de madera junto a cuerdas vegetales identificadas por andinistas en anteriores ascensiones, la que suponíamos, debía encontrarse al sureste de la plataforma junto a una zona de piedras tapada por la nieve (Figura 7).

En la misma ascensión se identificó un tramo de sendero entre 5200 y 5300 m.snm junto al glaciar Los Helados,

\footnotetext{
13 El testimonio de cumbre indicaba las anteriores ascensiones: Club Andino Mercedario (1971), expedición chilena (1981), Asociación Andinismo de Atacama (1984), expedición Daniel Valenzuela de Copiapó (1990), expedición Suiza-Argentina (1996) y expedición Ceruti/Manzi (2004).

${ }^{14}$ La posibilidad de que esta estructura haya servido como una caja ritual para ofrendas queda sujeta a futuras investigaciones. 


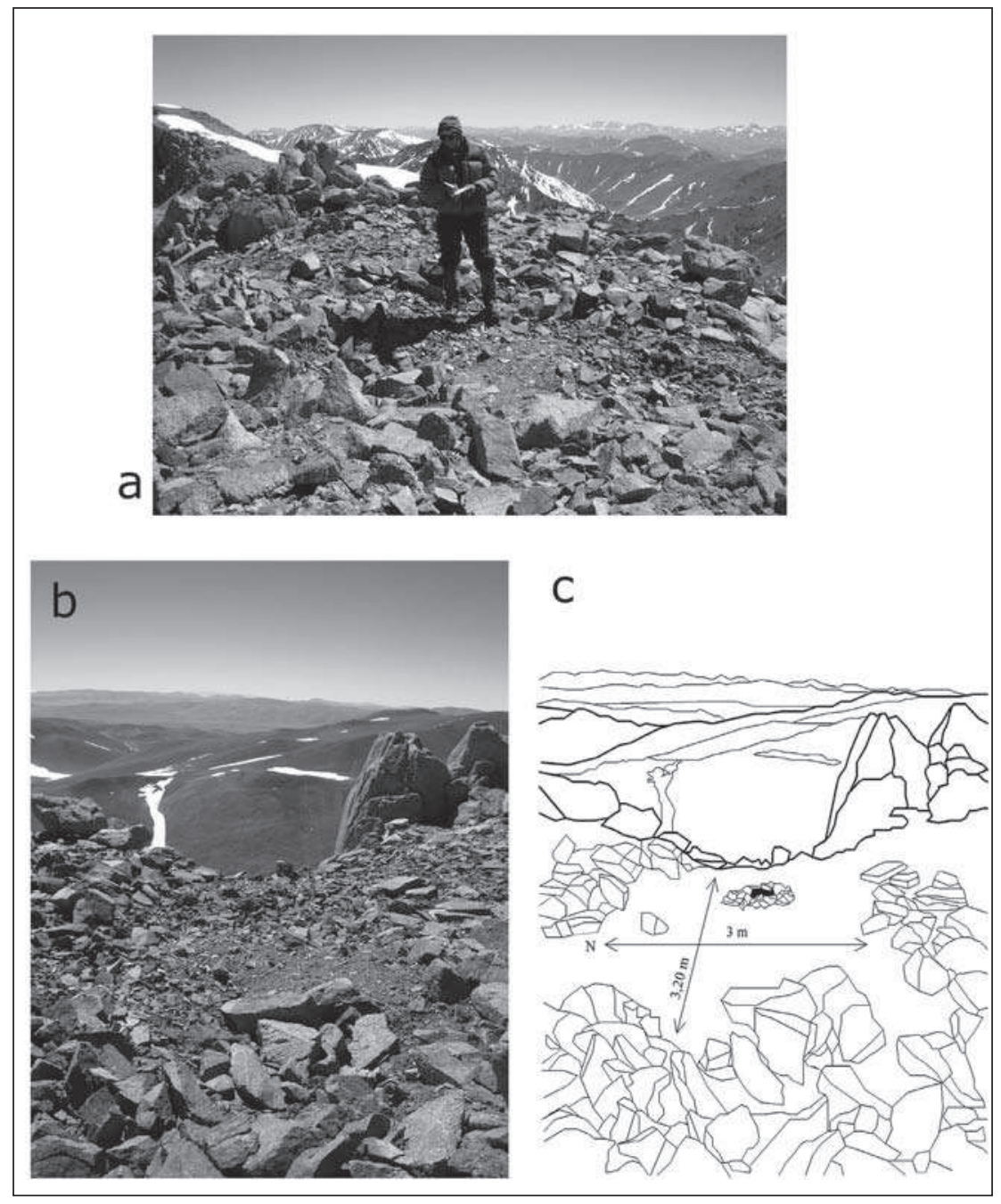

Figura 6. Plataforma del cerro El Potro: a) vista al norte; b) vista al este; c) representación gráfica, vista al este.

construido con la técnica del despeje simple..$^{15}$ Corresponde a una huella de $1 \mathrm{~km}$ de largo y ancho variable entre $70 \mathrm{~cm}$ y $1 \mathrm{~m}$, junto al flanco este del glaciar en una ladera de $30^{\circ}$ a $45^{\circ}$. En superficie no se observó material cultural ni elementos diagnósticos que permitieran su adscripción cultural (Figura 8).

En diciembre de 2005 también se inspeccionó el tambo Los Helados (UTM 436916 E / 6868253 N, 3730

${ }^{15}$ Coordenadas del trazado: UTM 441686 E / 6859986 N, 5312 m.snm; UTM 441739 E/ 6860180 N, 5262 m.snm; UTM 441748 E / 6860328 N, 5242 m.snm; UTM 441773 E / 6860790 N, 5207 m.snm.

m.snm), un conjunto arquitectónico emplazado en la ladera este del río del mismo nombre, sobre un sector de vegas y terrazas naturales. El patrón de construcción es típicamente incaico en la zona, de muros dobles con relleno y una gran plaza con recintos y patios adosados a ella (Figura 9). En superficie se identificó cerámica monocroma de paredes gruesas, escobillado interior y exterior, con tizne por uso, además de basura subactual. Desde allí es posible distinguir claramente la cumbre norte del cerro El Potro. ${ }^{16}$

\footnotetext{
${ }^{16}$ La cumbre norte del cerro El Potro tiene una forma cónica. Al respecto, sabemos que los incas consideraban especialmente sagradas aquellas formas del paisaje que además presentaban
} 


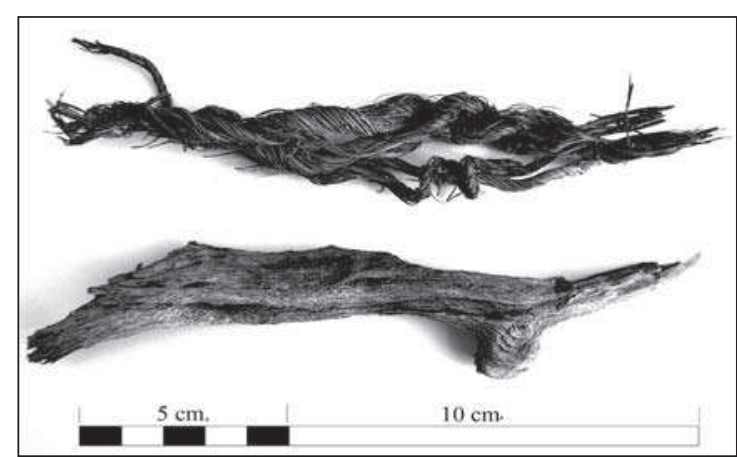

Figura 7. Madera y cuerda vegetal de cerro El Potro (colección Carmona).

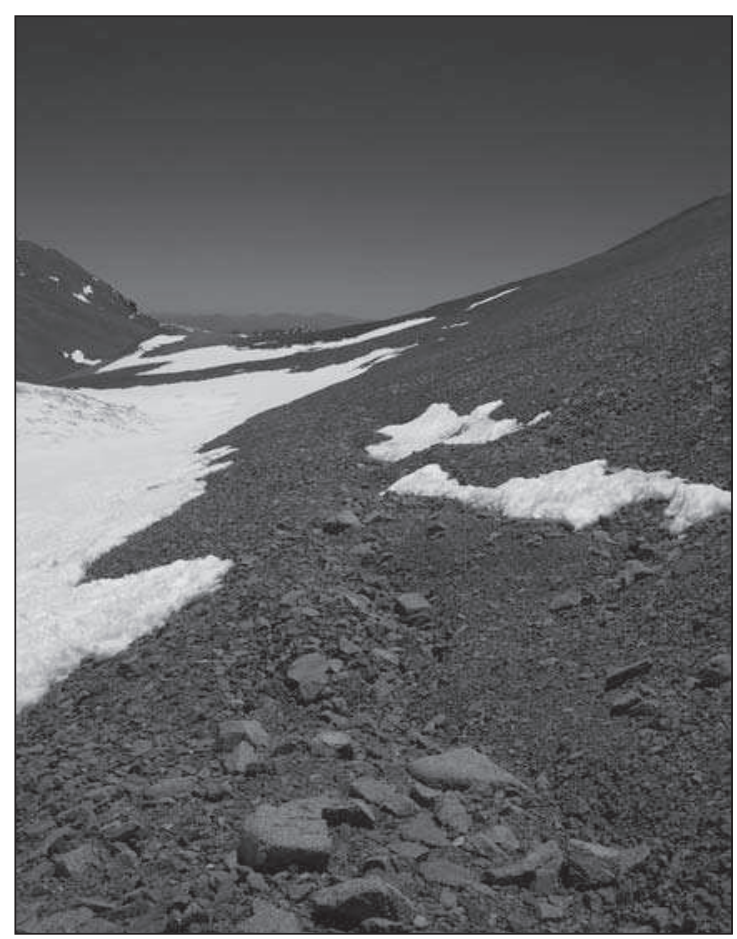

Figura 8. Sendero junto al glaciar Los Helados.

Tambería de los Helados se compone de cuatro unidades arquitectónicas (Figura 10; Niemeyer 1986: 195197). La unidad A está formada por dos recintos rectangulares contiguos que forman una "L". El mayor, con

tonalidades fuertemente rojizas (Gentile 1996), como el caso del volcán Licancabur en San Pedro de Atacama.

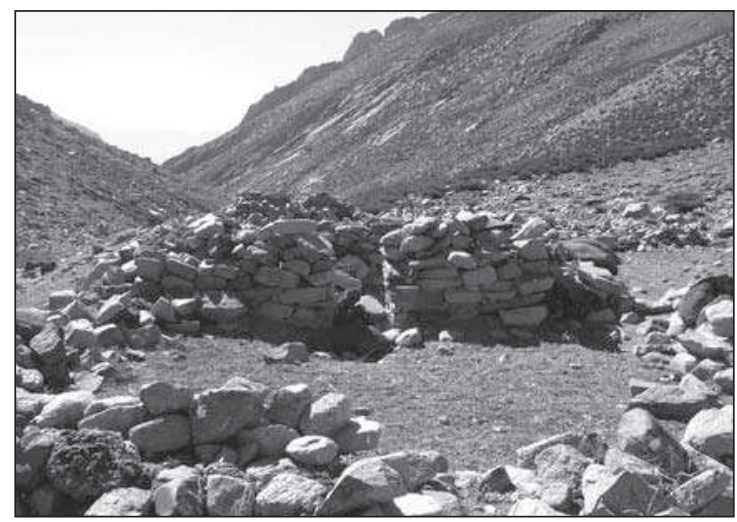

Figura 9. Muro sur de la estructura habitacional unidad B, tambo Los Helados.

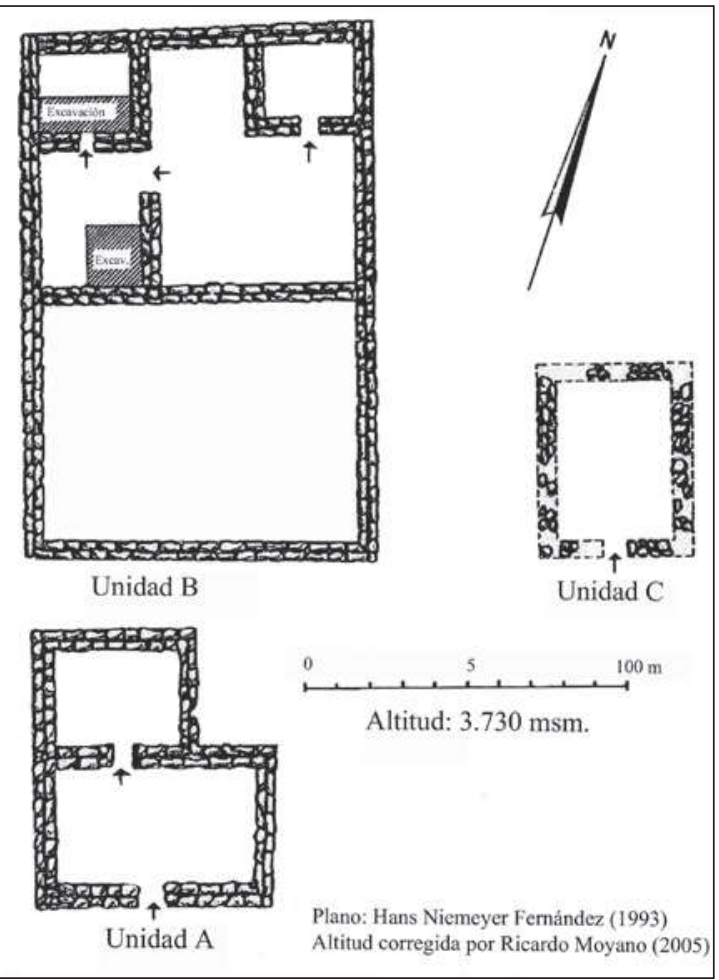

Figura 10. Tambo Los Helados. Dibujo tomado de Niemeyer y colaboradores (1993:360).

orientación este-oeste mide exteriormente $6.8 \times 5.2 \mathrm{~m}$, mientras que el rectángulo perpendicular a éste es algo menor, con dimensiones externas de 5.1 x $3.6 \mathrm{~m}$. Ambos están comunicados entre sí por un vano de acceso de 0.6 $\mathrm{m}$ de ancho al centro del muro sur. En el muro sur del recinto mayor también existe un vano central de $0.8 \mathrm{~m}$ de ancho, pero que comunica al exterior. 


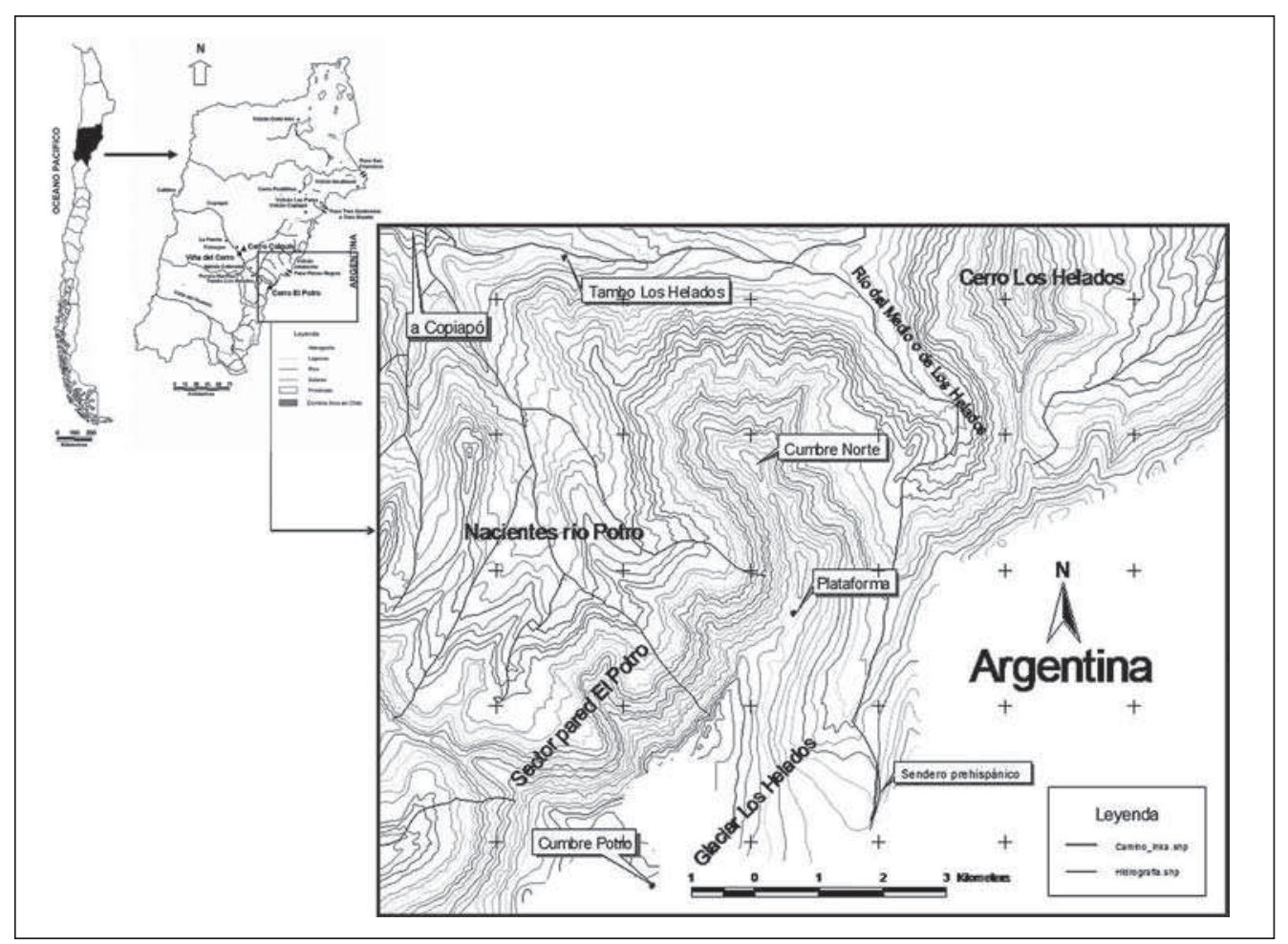

Figura 11. Distribución espacial de los sitios arqueológicos de cerro El Potro.

La unidad B está situada $6 \mathrm{~m}$ al norte y mejor conservada que la unidad A. Se compone de un muro perimetral que deja un espacio rectangular de 16.5 × 12.8 m y 11 m, además de divisiones interiores y dos recintos habitacionales de 4 x $3.6 \mathrm{~m}$, ambos con vanos de acceso central en su pared sur.

La unidad C está situada $5 \mathrm{~m}$ al oriente de la unidad B y corresponde a un rectángulo pircado de $4.8 \times 4.2 \mathrm{~m}$, en muy mal estado de conservación. También tiene muros de doble hilada con un vano de acceso en su lado sur.

La unidad D, no dibujada por Niemeyer, es un muro semicircular tipo paramento de $5 \mathrm{~m}$ de radio, ubicado $10 \mathrm{~m}$ al sur de la unidad A. En superficie se observó cerámica Diaguita Inca, doméstica y Copiapó Negro sobre Rojo.

\section{Palabras finales}

La montaña del Potro habría tenido una importancia ecológica, política y simbólica para los habitantes del valle de Copiapó en tiempos prehispánicos. La evi- dencia arqueológica recopilada primero en la vertiente argentina (Beorchia 1985), y posteriormente por andinistas y arqueólogos chilenos (Niemeyer 1986; Niemeyer et al. 1993; Moyano 2006) sugieren que este lugar fue un adoratorio indígena de alta montaña, al menos desde la llegada de los incas a la zona, ca.1470 DC (Figura 11).

El Potro no solo mantiene al glaciar Los Helados, uno de los más grandes del norte de Chile y que da origen a las aguas del río Copiapó, sino además, destaca en el paisaje local por mantener nieve gran parte del año, recibir los primeros rayos de solen las mañanas yadquiriruna tonalidad rojiza durante los atardeceres, visto desde la cuenca del río Copiapó. ${ }^{17}$ Este fenómeno es especialmente llamativo desde la parte media y alta de la cuenca, donde se tienen evidencias concretas de la presencia incaica en lugares

17 En algunos casos los incas no habrían buscado cumbres altas, pero sí muy llamativas en el paisaje local para la instalación de sus adoratorios. Este sería el caso del cerro Morado de Iruya a 5130 m.snm, donde afloramientos de tonalidades fuertemente rojizas contribuyeron a fijar la atención en la montaña (Ceruti 1999: 29).

No $38 / 2009$

EsTUdios ATACAMEÑOS

Arqueología y Antropología Surandinas 


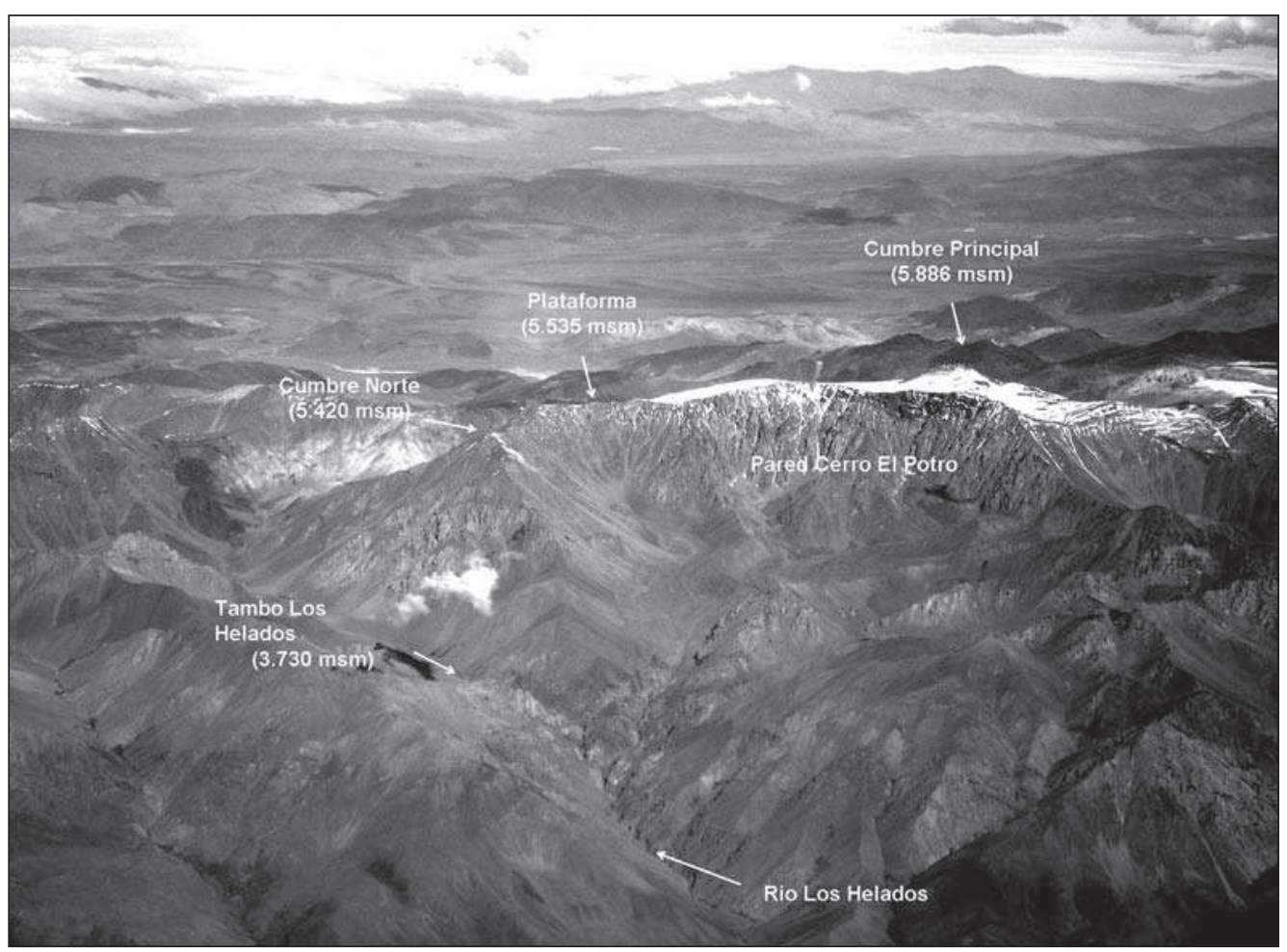

Figura 12. Vista aérea del cerro El Potro, vertiente chilena.

como La Puerta, Punta Brava, Viña del Cerro e Iglesia Colorada.

En términos logísticos la montaña no ofrece más dificultad técnica que su altitud y eventual cruce de glaciar, si se asciende a la cumbre desde las cabeceras del río Los Helados. ${ }^{18}$ Sus laderas, excluyendo el sector de la pared que enfrenta al valle de Copiapó, son suaves y poco escarpadas, posee abundante agua dulce y pastizales para el consumo humano y animal (Figura 12).

La existencia del tambo Los Helados a 3730 m.snm en la ruta de ascenso lógica desde el valle de Copiapó (Niemeyer 1986; Niemeyer et al. 1993) y de otras tamberías en el lado argentino (Beorchia 1985), dan cuenta de las condiciones relativamente benignas de esta zona de la cordillera de los Andes. A diferencia, por ejemplo, de los sitios ceremoniales identificados recientemente por Hershey

\footnotetext{
${ }^{18}$ Por el momento desconocemos la existencia de otra ruta de ascenso, sin embargo, no descartamos la posibilidad de una más directa desde las supuestas estructuras ubicadas bajo la pared a 4600 m.snm.
}

en las cercanías del volcán Incahuasi (com. pers. 2008) y de otros adoratorios en los volcanes Ojos del Salado y Copiapó (Beorchia 1985; Reinhard 1991; Moyano 2009).

La verificación de un sendero poco transitado a más de 5200 m.snm, junto al glaciar Los Helados, y la existencia de mejores pasos cordilleranos hacia el norte (Niemeyer 1986; Niemeyer et al. 1993), sugieren que este lugar no formó parte de un ramal trasandino del Qhapaqnan en el valle de Copiapó, sino una ruta con fines posiblemente ceremoniales como se ha planteado para otros adoratorios andinos (Stehberg 1995; Schobinger 1998). Esto es coherente con la ausencia de instalaciones logísticas en las inmediaciones del paso fronterizo $\mathrm{Na}$ cientes del Bermejo y en la cabecera del río Los Helados que pudieran haber servido como refugio en el contexto de vías transcordilleranas hacia el río Los Mogotes, o bien, como eventuales campamentos de acercamiento a la cumbre del cerro El Potro.

Asimismo, las noticias de un pequeño tambo a los pies de la pared del cerro El Potro, a 4600 m.snm, el hallaz- 
gode una plataforma y madera apilada a 5535 m.snm (Moyano 2006) y de un bastón de madera a pocos metros de la cumbre principal (Beorchia 1985) ${ }^{19}$, sugieren que esta montaña tuvo ascensiones semiperiódicas, realizadas por pocas personas y a través de distintas rutas. Pareciera que no tuvo una importancia principal, sino secundaria dentro del sistema de huaca en la región de Atacama, aun cuando es claramente visible desde el portezuelo Cantaritos en la parte alta de la cuenca del río Huasco, y desde el paso Pircas Negras (río La Gallina), en las inmediaciones del adoratorio Jotabeche.

La arquitectura ceremonial segregada ubicada en una de las precumbres a $5530 \mathrm{~m} . \mathrm{snm}$, indica que este lugar podría haber sido un centro de peregrinaje menor, de acuerdo a la clasificación de Ceruti (1999). Estas ascensiones tendrían que haber sido realizadas en los meses de verano cuando la alta cordillera presenta menos nieve y temperaturas más benignas, cercanas a la fecha del solsticio de diciembre, como sugiere Reinhard para las huaca del volcán Copiapó y nevado Jotabeche (1991), donde existen vestigios de una capacocha.

El argumento anterior se sustenta en los trabajos realizados en el centro metalúrgico Viña del Cerro (Moyano 2006, $2009 \mathrm{Ms}$ ), donde se constató la orientación orográfica de la arquitectura ceremonial y residencial hacia el cerro El Potro, junto con la existencia de marcadores de horizonte que habrían permitido conocer la extensión del año solar, y en particular la fecha del solsticio de diciembre, gracias a la salida del Sol por un contrafuerte del cerro Calquis en forma de "V" invertida (acimut de $110^{\circ}$ ).

Aún más interesante resulta el hecho que el cerro El Potro visto de Viña del Cerro aparenta la forma de un animal (con cabeza y lomo), es decir, la identificación de una forma conocida en el paisaje a partir de elementos aparentemente caóticos (Bustamante 2008). Esta idea alcanza validez si consideramos además, que la ubicación de la montaña del Potro coincide con la posición geográfica del polo sur celeste y con la constelación oscura de

${ }^{19}$ Una posibilidad es que este bastón de madera encontrado por los argentinos en 1971, fuera una especie de piolet de marcha que habría permitido avanzar por las rocas y asegurar el cruce de glaciar, después de lo cual fue ofrendado. la llama o Yakana (Moyano 2006). ${ }^{20}$ Esta zona del cielo se vincula con el culto a los ancestros, los ritos de pasaje, la fertilidad, los mitos de origen y la gran inundación en los Andes peruanos (Zuidema 1982). De ahí que nuestro argumento se oriente a la posibilidad que en tiempos prehispánicos se reconociera en esta montaña como un ser mítico, responsable del recurso hídrico y de los fenómenos meteorológicos en la cuenca del río Copiapó.

Con estos elementos de juicio, se sugiere que la montaña El Potro además de un lugar potencialmente sagrado o huaca, podría haber constituido un factor determinante en las relaciones de poder y reciprocidad entre las comunidades locales del valle de Copiapó y el Tawantinsuyo. En palabras de Ceruti (1999), este lugar habría materializado las "estrategias de dominación y resistencia" entre los incas, las élites y las comunidades locales, por cuanto representó un objeto de apropiación material, política y simbólica en las relaciones interétnicas de los grupos del valle de Copiapó. En otras palabras, un espacio físico para la realización de determinadas actividades, posiblemente ceremoniales, que incluyeron la participación de especialistas rituales y la movilización de recursos a los pies, laderas y cumbre de la montaña. Como complemento, también se habrían realizado ceremonias públicas en algunos lugares de la cuenca del río Copiapó, por ejemplo, en la cancha del centro metalúrgico Viña del Cerro (Moyano 2006, 2009 Ms).

Estas ceremonias habrían buscado incorporar el cerro El Potro a los ritos anuales de fertilidad y al agua a través de la construcción de un sistema de líneas visuales (posiblemente ceques) proyectadas desde el complejo ushnucancha en Viña del Cerro. Este microsistema habría simbolizado la presencia del Tawantinsuyo en la cuenca del río Copiapó, restableciendo el orden cósmico y propiciando desde un centro ceremonial a otro (Viña del Cerro-cerro El Potro) los fenómenos meteorológicos, el recurso hídrico, la actividad metalúrgica y la regeneración del recurso minero en la cuenca del río Copiapó.

Agradecimientos Al Museo Regional de Atacama, a la Rama de Montaña de la Universidad de Chile, al Gobierno Regional y a la Corporación Nacional Forestal de la

${ }^{20}$ Las estrellas $\alpha$ y $\beta$ Centauro o llamaq ñawin representan los ojos de la llama celestial. 
Región de Atacama, por facilitar el transporte y equipamiento de alta montaña. A los andinistas y amantes de la arqueología: Juan Carlos Carmona, Dagoberto Lezcano, Rodrigo Zapata, Michael Wolfe y Felipe Gutiérrez por su participación en las campañas de terreno. A los investiga- dores Tom Zuidema, Patricio Bustamante, Alejandra Sejas y Francisco Garrido por sus comentarios, sugerencias y ayuda en la edición del manuscrito. En particular a mi familia y a Kate Grim-Feinberg, por entender y compartir mis sueños.

\section{* Referencias citadas}

BARÓN, A. y J. REINHARD, 1981. Expedición arqueológica al volcán Licancabur. Revista de la Corporación para el Desarrollo de la Ciencia 1 (4):31-38.

BEORCHIA, A., 1985. El enigma de los santuarios indígenas de alta montaña. Revista del Centro de Investigaciones Arqueológicas de Alta Montaña (CIADAM) 5 .

2001. Inventario de los objetos descubiertos en los adoratorios indígenas de altura. Revista del Centro de Investigaciones Arqueológicas de Alta Montaña (CIADAM) 6:281-214.

BUSTAMANTE, P., 2006. Hierofanía y pareidolia como propuestas de explicación parcial a la sacralización de ciertos sitios por algunas culturas precolombinas de Chile. http://www.rupestreweb.info/hierofania. html (marzo 5 de 2008).

2007a. Pareidolia y apofenia como fenómenos extendidos y como herramienta de análisis de obras rupestres y sitios arqueológicos pertenecientes a diversas culturas. http://www.rupestreweb.info/pareidoliaz. html (marzo 5 de 2008).

$2007 \mathrm{~b}$. Aplicación del concepto "entorno" al análisis e interpretación de los sitios Los Mellizos y Las Bellacas, Alto Río Illapel, IV región, Chile. http://www.rupestreweb.info/entornoz.html (marzo 5 de 2008).

2008. ¿Qué parece? Como pregunta orientadora en el estudio de la topografía sagrada en la cultura azteca. http://www.rupestreweb.info/ queparece.html (marzo 31 de 2008).

CANTARUTTI, G., 2006 Ms. Informe de visita arqueológica: Curso superior del río Los Helados-paso fronterizo Nacientes del río Bermejo, región de Atacama, "Proyecto Minero Vicuña, Sector Los Helados". Consejo de Monumentos Nacionales, Santiago.

CASTILLO, G., 1997. Los períodos Intermedio Tardío y Tardío: Desde la cultura copiapó al dominio inca. En Culturas prehistóricas de Copiapó, H. Niemeyer y M. Cervellino (Eds.), pp. 163-282. Museo Regional de Atacama, Copiapó.

CASTRO, V. y C. ALDUNATE, 2003. Sacred mountains in the highlands of the South-Central Andes. Mountain Research and Development 23 (1): 73-79.

CASTRO, V., L. CORNEJO, F. GALLARDO y F. ARNELLO, 1986. Santuarios de altura en la subregión del río Salado: Contexto arqueológico e ideología. Chungara 16-17:347-352.

CERUTI, M. C., 1997. Arqueología de alta montaña. Editorial Milor, Salta.

1999. Cumbres sagradas del Noroeste Argentino. Eudeba, Buenos Aires.

2003 Santuarios de altura en la región de la laguna Brava (provincia de la Rioja, Noroeste Argentino). Informe de prospección preliminar. Chungara, Revista de Antropología Chilena 35 (2):233-252.

CERVELLINO, M., 2001. Santuarios (¿adoratorios?) de altura. Revista del Centro de Investigaciones Arqueológicas de Alta Montaña (CIA$D A M) 6: 183$.

DELGADO, I., 2001. Noticias de nuevos descubrimientos. Revista del Centro de Investigaciones Arqueológicas de Alta Montaña (CIADAM) 6:267-279.

GENTILE, M., 1996. La dimensión sociopolítica y religiosa de la capacocha del cerro Aconcagua. Bulletin de l'Institut Français d'Etudes Andines 25(1): 43-90.

HYSLOP, J., 1990. Inka settlement planning. University Texas Press, Austin.

1992. Qhapaqñan, el sistema vial incaico. Instituto Andino de Estudios Arqueológicos, Petróleos del Perú. Epígrafe S.A. Editores, Lima.

LEONI, J., 2005. La veneración de las montañas en los Andes preincaicos: El caso de Ñawinpukyo (Ayacucho, Perú) en el período Intermedio Temprano. Chungara, Revista de Antropología Chilena 37 (2): 151-164.

LE PAIGE, G., 1978. Vestigios arqueológicos en las cumbres de la zona atacameña. Estudios Atacameños 6:36-51. 


\section{RicARDo MOYANO}

MARTÍNEZ, G., 1976. El sistema de uywiris en Isluga. En Homenaje al Dr. Gustavo Le Paige s. j., J. M. Casassas (Ed.), pp. 255-327. Universidad del Norte, Antofagasta.

1983. Los dioses de los cerros en los Andes. Journal de la Societé des Americanistes LXIX: 85-115.

MEDDENS, F. M., 1997. Function and meaning of the usnu in the Late Horizon, Peru. Tawantinsuyu 3: 5-14.

MOYANO, R., 2006. Sol, luna y huacas en el valle de Copiapó: El ushnu de Viña del Cerro como lugar de observación astronómica y culto a las montañas en Atacama. Memoria para optar al título de arqueólogo. Facultad de Ciencias Sociales, Universidad de Chile, Santiago.

2009 Ms. El ushnu y la astronomía de horizonte en Viña del Cerro. 2009. Adoratorios indígenas en la III región de Atacama: Resultados preliminares del reconocimiento arqueológico del cerro Pastillitos y volcán Los Patos, Werken 12. En prensa.

NIEMEYER, H. 1981 Descripción de la hoya hidrográfica del río Copiapó. Contribución Arqueológica 2: 27-141.

1986. La ocupación incaica de la cuenca alta del río Copiapó (III región de Atacama, Chile). Comechingonia núm. especial: 165-294.

NIEMEYER, H., M. CERVELLINO y G. CASTILLO, 1993. Estrategia de dominio inca en el valle de Copiapó.Actas del XII Congreso Nacional de Arqueología Chilena vol. 1, pp.333-371. Temuco.

2003 Ms. Pucara del río Manflas y otros complementos de la prehistoria del valle de Copiapó, III región de Atacama. Informe FONDECYT 1000037, Santiago.

PINO, J., 2005. El ushnu y la organización espacial astronómica en la Sierra Central del Chinchaysuyu. Estudios Atacameños 29: 143-161.

PISSIS, P., 1875. Geografía fisica de la República de Chile. Instituto Geográfico de París, París.

REINHARD, J., 1983. Las montañas sagradas: Un estudio etnoarqueológico de ruinas en las altas cumbres andinas. Cuadernos de Historia 3: 27-62.

1991. Investigación arqueológica de las plataformas ceremoniales en los volcanes de Copiapó y Jotabeche (región de Atacama). Contribución Arqueológica 3: 29-89.

1992. An archaeology investigation of Inca ceremonial platforms on the Volcano Copiapo, Central Chile. En Ancient America:
Contribution to New World archaeology, N. Saunders (Ed.), pp. 145172. Oxbow Books, Oxford.

2001. Sobre los volcanes Coropuna, Copiapó, Jotabeche, Llullaillaco y Ampato. Revista del Centro de Investigaciones Arqueológicas de Alta Montaña (CIADAM) 6: 103-146.

RISOPATRÓN, L., 1924. Diccionario jeográfico de Chile. Imprenta Universitaria, Santiago.

SCHOBINGER, J., 1986. La red de santuarios de alta montaña en el Contisuyo y el Collasuyu: Evaluación general, problemas interpretativos. Comechingonia núm. especial: 297-317.

1998. Arqueología de alta montaña. Santuarios incaicos en los Andes Centro Meridionales. En Beiträge zur allgemeinen und vergleichenden archäologie, Band 18, pp. 363-396. Deutshen Archäologischen Instituts, Bonn.

1999. Los santuarios de altura incaicos y el Aconcagua: Aspectos generales e interpretativos. Relaciones de la Sociedad Argentina de Antropología 24: 7-27.

2001. El santuario incaico del cerro Aconcagua. EDIUNC, Mendoza.

STEHBERG, R., 1995. Instalaciones incaicas en el norte y centro semiárido de Chile. Dirección de Bibliotecas, Archivos y Museos, Santiago.

STEHBERG, R. y G. SOTOMAYOR, 1999. Cabis, guacas-fortalezas y el control incaico del valle de Aconcagua. Estudios Atacameños 18: 237-249.

URÍZAR, M., 2002 Ms. Período de contacto indígena: La colonización española en el valle de Copiapó. Informe FONDECYT 1000037 , Santiago.

WILLIAMS, P. y D. NASH, 2006. Sighting the apu: A GIS analysis of Wari imperialism and the worship of mountain peaks. World Archaeology 38 (3): 455-468.

ZUIDEMA, T., 1982. Catachillay: The role of the Pleiades and of the Southern Cross, and Alpha and Beta Centauri in the calendar of the Incas. En Ethnoastronomy and archaeoastronomy in the America Tropics, A. Aveni y G. Urton (Eds.), 358: 203-229. Annals of the New York Academy of Sciences, Nueva York.

1995 [1964]. El sistema de ceques del Cusco. Pontificia Universidad Católica del Perú, Lima.

2009. El calendario inca. Fondo Editorial del Congreso de Perú, Lima. En prensa. 